THE SOUTHPORT AQUARIOM AND WINTER GARDEN.|SOLPHUR IN SICILY, AND ITS REDUCTION FROM THE| A few miles to the north of Liverpool, on the Lancashire coast, England, is a newly grown watering place, Southport. Its beauty and salubrity have gained it renown among the inhabitants of the scores of manufacturing towns in its immediate neighborhood; and it has become a very popular resort, being within a short railway journey of the homes of many millions of people. The Southport folks have recently embellished their town with a building comprising an aquarium, a winter garden, a muaic hall, and a large covered our Fig. 1, is a large and graceful structure of iron and glass, , gneiss and slate. On these sandstones are marl beds, which and resemble keuper marl; then follow limestones both jurassic other plants, but also birds and animals, mate his been wisely entrued to the con. This Frauk Buckland, the friend of all living creatures and the editor of Land and Water.

The aquarium, Fig. 2 , is excellently ar ranged, being mainly lighted through the tanks containing the specimens, so that they may be seen to advantage. It is a solid and imposing structure. The exterior of the building, with the entrance gates and a portion of the grounds, are shown in Fig. 3.

"The edifice," says Mr. Buckland, "must be inspected to obtain an idea of its beauty. In general outline it reminds us of the Crystal Palace. One side only of this crystal palace is at present in existence, but there i ample space (now occupied by houses) to complete the other wing.

Adjoining the dome is a promenade, which at the night of opening was so full that it wa almost impossible to move about. On the walle of this Rolfe Rolfor the picture I cast in the Ness, 32 pounds in weight. I cast him. Mr. Rolfe painted him in his best style, and we conjointly had the pleasure of presenting him to the aquarium. He is represented as lying in a basket on straw, and the deception, to those who had never seen Mr. Rolfe's works before, was very satisfactory, the difficulty being to prevent people from tapping the fish to see if it was real. A glass case is being prepared for its reception.

The squarium cannot be seen from above ground. The space underneath the winter garden is entirely occupied by an immense tank for sea water; it communicates with two other tanks which are used as occasion requires.

The sea water is supplied from the pub lic baths, whence it is conveyed by means of a pipe; abundance of water is available

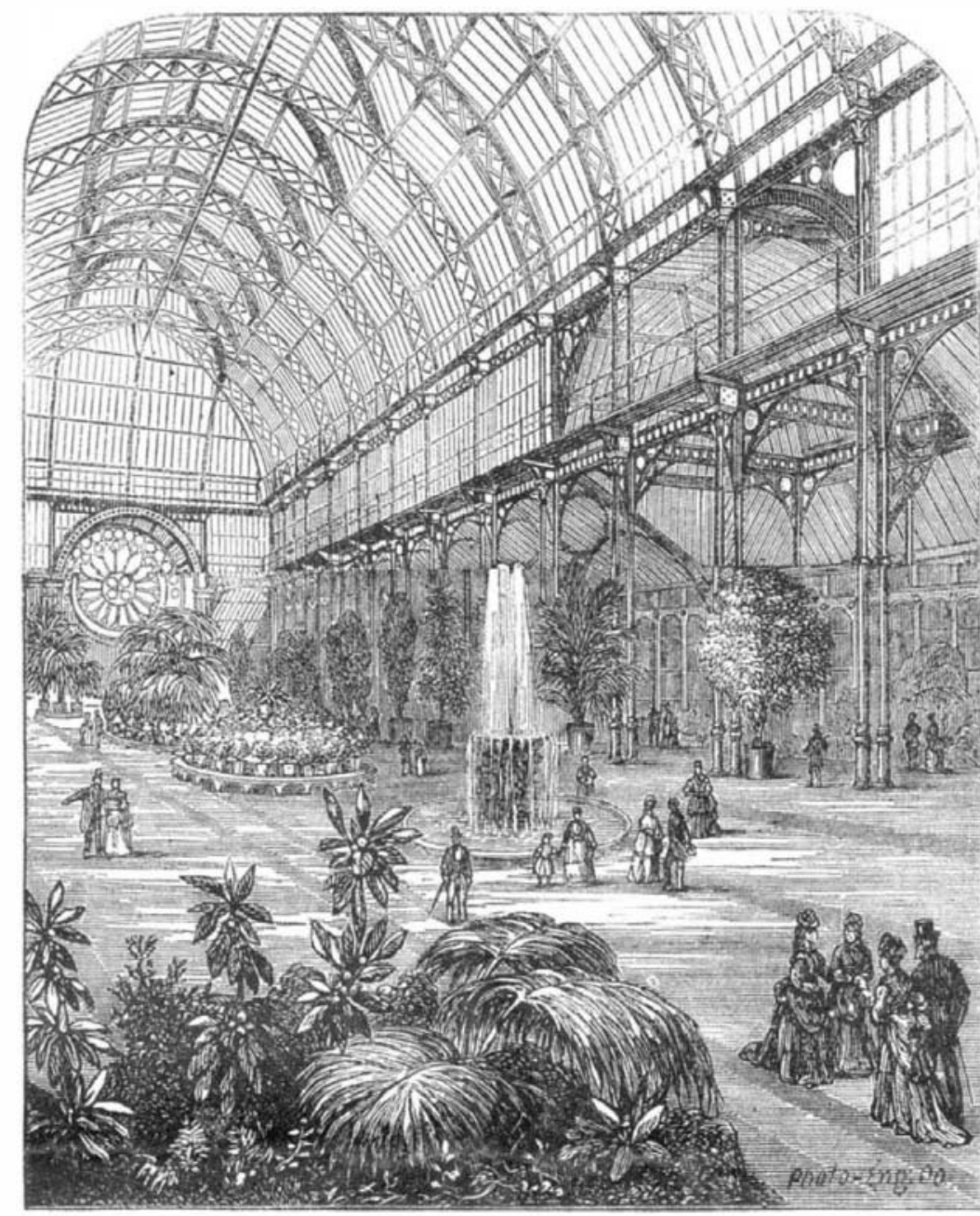

SOUTHPORT, ENGLAND.-Fig. 1.-THE CONSERVATORY.

wood. The thickness of the sulphur deposit, in its frequently recurring changes, often remains very constant, and indi. cates an equally regular change in the conditions under which it was deposited; it almost reminds a person of the

The strata in which the sulphur occurs belong to the ter- changing seasons. The fishes found in the sulphur mar ary formation, and, according to Mottura, to the miocene enable us to recognize the sulphurous strata as formed by epoch. They extend over a large portion of the island, the fresh water

Parodi states that the average percentage of sulphur in the

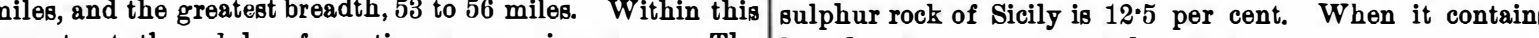
less than 6 per cent of sulphur, it do 13 not pay for mining and smelting. In 1871 , Sicily produced 150,000 tuns of sulphur, probably nine tenths of that produced in the whole This production is continually increasing. That wealth does not prove a greater blessing to the country and its prosperity is principally due to the circumstance that in Sicily the property on the surface cannot be released from that of subterranean treasure, and this circumstance results in a number of other evils, which do not permit mining to emerge from its great and almost inconceivable imperfection.

The namber of sulphur mines in Sicily is upwards of 600 , not more than half of which are worked at present; and of these, only about 50 are of considerable importane,

In looking for the sulpbur deposita, a soft kind of gypsum, formed by the decomposition of the sulphur.bearing lime or calcareous marl, plays an important part. In geveral, the sulphur is combined with gypsum, and the presence of the latter renders it probable that the former is near. To reach the depos its, inclined shafts are dug, having an incli nation of $25^{\circ}$ to $50^{\circ}$, seldom steeper, and more seldom horizontal. Neither horizontal galle ries nor vertical shafts are employed, since the former would not reach the sulphur soon enough, and the latter would require the use of some sort of machinery; and wood is lack. ing for this purpose, as also for timbering and frame work. Steps are cut into the inclined plane, and when it is not steeper than $45^{\circ}$ the steps reach all the way across; but when steeper, two steps are cut side by side, alternating with each other. The young laborer climb up and down these high, narrow, and slippery steps, panting, groaning, and sweating-carrying on their heads and backs heavy bags filled with sulphur ore. They make from 16 to 18 ascents and descents daily, to and from a depth of over 200 feet.

By this pitiable method, at least a million tuns of sulphur ore are annually brought up into the light of day by boys and youth Nay, too, the little drippinge of water are collected in stone jugs, and brought up in the same laborious manner. The mine is almos always abandoned when it reaches the water from this source. The aquarium itself under the winter culiar porous limestone in crase and ridges, On the top of the level, The temperature in these is vory high, $111^{\circ}$ Fah partly under the promenade and partly under the wiser the gardens. Under the promenade are twenty-two tanks, the latter is a foraminferous marl of marine origin, after which renheit, and, owing to the moisture in the air, it is algas at night.

The fish in the various tanks are as follows: Congers, lin and codling, mullets, father lashers, sea trout, wrasse, anemones and whiting, dog fish, gurnards, crayfish and crabs, whiting, rays and soldier crabs, soles, turbots and flukes, monkfish, topers, lobsters, king crabs, octopus, Maia squina do and edible crabs, stickle backs and anemones, bass or sea perch, cod, salmon, great lake trout, and gold schlei golden tench, and large dog fish.

follows a stratum of tripoli, upon which is a stratum of cal. most unendurable. The diggers (picconieri), owing to the careous marl, which is in some places more argillaceous, in
others more calcareous. This is the stratum which contains
phur rock is so soft that it is cut out with a large instrument others more calcareous. This is the stratum which contains phur rock is so soft that it is cut out with a large instrument the sulphur. The sulphur formation is generally covered like an ax. The roof of the mine is supported by pillars, so over with immense masses of gypsum, on which again is a that a considerable portion of the ore is left standing, to seforaminiferous marl. Then follows the pliocene formation, cure the structure. In order to obtain the mass of the pil. liag, and yellow breccia. found in widely distant portions of Sicily, were formed at is left for a time, until it adheres together; shafts and palthe same time as the deposits of sulphur. The rock leries are then dug through it to get at the pillars. When

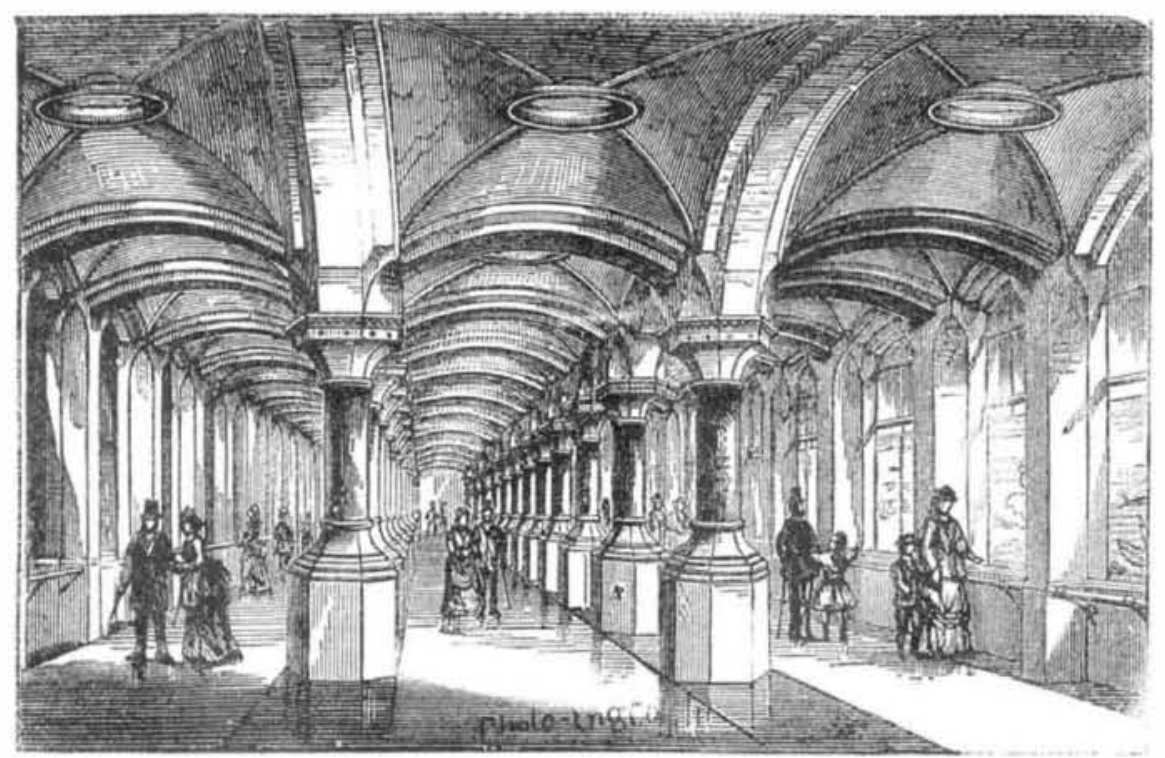

Fig. 2.-THE AQUARIUM.

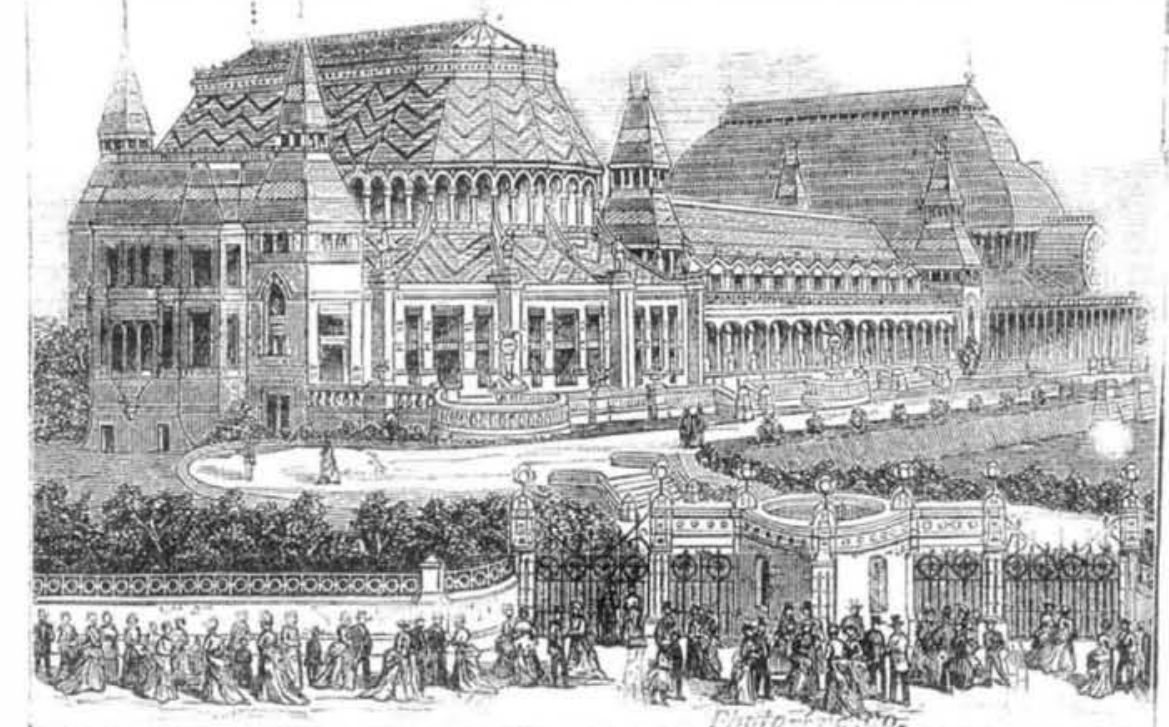

Fig. 3.-EXTERIOR OF THE BUILDING.

There are also some very handsome table tanks and |salt enclosed in the clay strata is often very pure. The| the sulphur-bearing strata lie one above another, there isa aquaria, containing collections of anemones, gobies, fifteen deposits of sulphur are not usually of great extent, and double set of pillars. Through errors in the ground plan spine sticklebacks, prawns, and Norway lobsters. Orders do not seem to bs in immediate communication. The and ignorance of mining surveying, it generally happens and regulations have been laid down by the board as to feed. sulphur impregnates the ${ }^{\top}$ strata of clay and limestone, ap. that the pillars in the upper gallery do not agree with those ing the fish, cleaning the tanks, etc. There is a seal tank, pearing either in irregular threads and veins, or in layers in the gallery below. As the stone is often soft and brittle, and some fine specimens of the sea trout.

AN Illinois editor returns thanks for a centipede sent to him by mail from Texas, "it being," he says, "the first cent of any kind that we've received for several woeks." three to six feet thick, elternating with the llayers of rock, it is no wonder that they frequently break through. or in round concretions from 0.4 to 0.8 of an inch in diameter. The condition of the sulphur miners is extremely deplore Barytes and imperfect cryatals of calxepar accompany the ble. The manner of living in populous spots miles distant sulphur, and, more rarely, beautiful crystals of colestine. from each other, instead of in villages, is peculiar to that Sometimes the sulph ur strate enclose whole stems of fossil country, and the majority of the mines are far distant from 
human dwellings. Neithermanager nor contractor consider lence have tended to highten popular interest in the exhibi. it a duty or necessity to erect a roof to protect their work- tion, apart from that excited by its partaking of the nature men, so that they sleep in the open air in pleasant seasons, of an international contest. A new object of curiosity has
exposed to the damp dew; while in winter they sleep in the been recently added in the shape of the winning boat of the foul atse itself, exposed to the dangers of being buried alive. In cases of sickness, the unfortunates have no assistance, and the families of those who die, or are killed, are exposed to the greatest misery. As regards edukilled, are exposed to the greatest misery. As regards edu-
cation and moral instruction, the working classes are entirely neglected; there are no schools, savings banks, or associa. neglected; there are no schools, savings banks, or associa.
tions for mutual aid. The consequence is that the society tions for mutual aid. The consequence is that the society which grows up about the sulphur mines is in every respect an abandoned class, ripe fur crime.
for evil doers from the whole island.

The sulphur is prepared throughout Sicily by melting the stone in calcaroni, where the combustion of a portion of the sulphur furnishes the necessary heat to fuse the remainder. The liquid sulphur drips down to the bottom, and flows out into molds intended for its reception. In building a calca rone, a spot is selected at the side of a hill, and a cylindrical furnace built, from 20 to 40 feet in diameter, and a few yards in hight. The walls are supported in the rear by
the earth, and in front project in a semi-circular form. The hearth of the furnace has a double inclination, from the hil toward the front and from the sides toward the middle, so that the liquid sulphur collects in one place, and tbrough a perforation in the inner wall it reaches the outlet. The bottom is pounded down hard like a threshing floor. The interior is filled with sulphur ore, the larger pieces being thrown in just as they are, and the smaller ones are formed into cakes, so that the melted sulphur will flow down through it cakes, so that the melted sulphur will flow down through it more readily. When the cylinder has been filled, the pieces of sulphur ore are heaped up in a cone above the mason work, and

operation.

A calcarone will hold from 175 to 1,750 tuns. In charging he furnace, several vertical flues are left open, which serve in part for kindling the fire, and in part to keep up the com. buetion at the beginning of the operation. The pile is ignited by throwing burning wood or bundles of straw down these openings. When the whole mass gets to burning, all the openinge are closed; and the operation, which lasts from two to four weeks, according to size, is attentively watched,
and the combustion controlled by the cover on the heap. and the combustion controlled by the cover on the heap. since sulphur melts at $240^{\circ}$, and remains a thin fluid up to a temperature of $320^{\circ}$. The melted sulphur is drawn off through a hole a foot wide and two feet high, in the front of the furnace, which is previously stopped with clay. The sulphur is run into wooden molds, the bottom and sides of sulphur is run into wooden molds, the bottom and sides of
which are moistened so that the sulphur cake will not adhere so tightly.

This method of obtaining sulphur is attended with a great deal of lozs; experience shows that the highest yield of a calcarone is 70 per cent, although it does not usually exceed 50 per cent of the total amount of sulphur. The crude sul-
phur is worth from $\$ 180$ to $\$ 2$ per 225 lbs., so that the fuel consumed is worth at least twice as much as English cos would cost in Italy.

In producing sulphur in Sicily, only those resources to be found on the spot are made use of : no wood for framing, no machinery for raising the ore and water, no coal for smelt. ing. Any one who would attempt to introduce any improvement in mining or reducing the sulphur would encounter great difficulty, arising rhiefly from relations of proprietor ship, and in the social status of the country. Legislation is the only help. Notwithstanding the immense store of natural sulpbur on the island, it will be seriously impaired, by the progress in other countries which now make oil of vitriol from

THE FAIR OF THE AMERICAN INSTITUTE.

The A merican Ingtitute Fair is proving remarkably ouc-

The American Institute Fair is proving remarkably suc-
cessful, if we may judge from the large crowds which constantly throng the building. The display is unquestionably the best that has been made for many years; and since it includes a number of industrial processes carried on in presence of the visitors, itcalls forth a much morelively interest pleted products. At one portion of the hall,ivory turners are at work,making billiard balls and carving ornaments; at another a newspaperoffice is shown in full operation, from the editor vainly endeavoring to seize vagrant ideas-a dificult task, and one we should unhesitatingly decline under the the circumetances, for we doubt if we could work with bevy of bright eyed damsels staring at us-to the finished sheets deftly piled by the swift.running press. There are tailors cutting out garments by machinery, brush makers manufacturing brushes of all kinds, scroll saws cutting out wooden ornaments and trinkets, engravers making illustrations similar to those in our pages, confectioners cooking candy, and even an old gentleman who cuts your profile likeness in black paper, and does it admirably too, in half a minute, for a small consideration. Up in the Art Department arelargevolumes, each leaf of which shows an application of one the numerous tints imprinted on a well known chromo. By studying the pages the visitor can learn in a very short time just how the very handsome works of art
which Mr. Prang exhibits are made, and how laborious the task must be.

Thereare a pumber of interesting shoemaking and leatherworking machinss in the main hall, and a superb display of leather. Hides tanned by the best American processes are brought in direct competition with those i ported from in
Europe, and the special medals which are offered for excelmention.
men of which our limited sOILES,
THE ICE CREAM MACHINE Columbia crew at the Saratoga Regatta, last summer. It ays acrose the hall, gaily decorated with blue and white variety of miniature steam machinery exhibited in opera variety of miniature steam machinery exhibited in opera-
tion. There is a steam fire engive which tbrows a needlelike stream for several yards, steam propellers which travel uite rapidly about a tank of water, and a small machine hop, including lathes, saws, etc., the tools all run by a ting boiler. Mr. Hawkins, the Superintendent of Machinery,also aims at popularity among the children, for he has lately devoted his ingenious button mold machine to the manufac-
ure of some queer games, which are very interesting, and beside has produced skipping ropes of a remarkable an hitherto unknown pattern.

The Fair as a whole is admirable, and the exhibitors hav airly outdone themselves in the elaborate and tasteful plan dopted in showing their contributions. The managemen is open to improvement, particularly with reference to al-
lowing the woodworking people to howl their wares like country showmen, to the individual with the perfumery who squirts cold spray into peoples' ears or eyes,and in regard to that ugly'drapery on the roof ; and there are ridiculous advertrements which talk about "enormoas fish" in that little
ountain; but generally, however, we find a great deal to praise and verylittle to condemn.

A recent atroll through the Machinery Department ha lled our note book with descriptions of a score or more interesting.

\section{The MACHINE TOOL}

ritical examination. thus affording excellent opportunities for the mecbanic to watch their practical employment. There is a chucking and turning lathe, by which a hole can be bored or chucked 20 inches in diameter; and by means of a new slide turning rest, a pulley can be turned, baving a diameter of from 8 to 30 inches. This machine has a gap bed. In the upright drills there is a steel drilling spindle attached to a gibbed drills there is a steel drilling spindle attached to a gibbed
head which moves up and down with the spindle,giving the atter a very long bearing at every point. A number of macbines which have been illustrated in our volumes are exgear-molding machine. The shapers have their cuttin bars placed on edge in adjustable guides. The vibration or spring of the tool is prevented by placing the widest secion of the bars directly opposite the cut. The box-boring machine is arranged so that either of two bars may be used in boxes in each rest may be simultaneously operated upon. boxes in each rest may be simultaneously operated upon.
The 9 inch bending rolls exhibited are so constructed as to be kept in constant contact with the plate, and their spring ing at the centers is prevented. There are a number of other

employed to supply steam to the main engines, are of the Howard eafety type. Five tiers of tubes which incline up. ward to the rear are connected to vertical sections by boring malliholes in the extremities of the tubes and allowing th cast metal of the sections to flow in,forming a perfectly solid
joint. The parts of the vertical sections are bound together by stay rods passing through and set up with brass nuts and the caps opposite the parts where the tubes enter are similarly attached by rods passing length wise through the rear of wbich the heat passes and then encounters anotber
rearese diaphragm, above the third tier. The products of combue tion are then conducted to the front of the boiler, whence tion are then conducted to the front of the boiler, whence they return to the uptake. The three lower tiers of tube
are for water and the upper 'ones for steam, the latter hrough the disposition of the heat, becoming highly heated. There are three

\section{CURIOSITIES IN THE"MACHINE DEPARTMENT.}

The first is a large tank provided with windows and filled with water. In this the Myers rotary engine is soon to rotate a good sized propeller, and brilliant lights are to be
placed so as to shine down and through the water. This is an ingenious way of loading the engineand, besides,showin its adaptability to marine purposes. The tank, howev looks somewhat fragile; extra riveting might improve it. found in the second of our trio of curiosities. It is

THE DIAMOND BAND SAW.

There is little in the construction of this machine, save nary woodworking tool. The blade, however, instead of being a single strip of metal, is a band covered with small straps of steel, the latter strung on the former, like beads In certain straps the diamonds-borts or carbons-are seIn certain straps the diamonds-borts or carbons-are se-
cured so that three straps containing diamonds may come together,and then an interval to the next set occurs of som
eightinches. There are of course other ways of arranging the diamonds, which need not here be described. The ma chine cuts a curve or scroll in stone as easily as the ordinary band saw goes through wood. A certificate published by that the blade cut through Newark brown stone, measuring feet $2 \frac{1}{2}$ inches one way and 3 feet 3 inches the other, mak ing a superficial surface of $1,501 \frac{1}{2}$ squareinches, in 22 minutes time. of Messre. Dixon and Tonstill is the last odd invention of the three. The prepared materials are dropped into a can flow through a tube into a horizontal cylinder which is placed in a tub and covered with ice and salt. Inside the cylinder is a helicodal knife, which scrapes the edges and also forces out the frozen material through one end. Both cylinder and knife are rotated by simple gearing. It is quite curious to watch the materialsenter one part of the machine, and quickly emerge in a frozen condition from another, in the shape of excellent ice cream.

There are two

PIPE CUTTING AND THREADING MACHINES

which deserve notice. One is that of the Chase Manufacturing Company, illustrated on page 131 of our last volume. In this the pipe is held stationary in the vise, and passes through the center of a gear, the rotary motion of which is imparted to the die in the die box by means of guides, upon which the die box freely slides forward as the die passes
upon the pipe. When cutting pipe, the tool post, with the cutter, has an automatic feed.

The manufacturers of the other machine are N. W. Frost The manufacturers of the other machine are N. W. Frost
\& of Cohoes N. Y. Theapparatus is in three pieces, readily taken apart and put together. One portion forms anexcellentrise; another is inserted above and carries the handle and a pinion; and the third is the gear wheel, in which the pinion engages, and which turns the dies and
operates the feed. The machine does excellent and rapid work, and is very simpleand strong in construction.

THE MAXIM AUTOMATIC PUMPING ENGINE

is a novelty recently added. It consists of a little steam boiler heated by gas, which warms and regulates its own feed and controls the fire. It runs a little pump, placed above, which is said to be capable of forcing from ten to a cost not o ver 6 cents.

\section{New Camera Lucida for Drawing.}

It is known that the construction of the camera lucida is founded upon the simultaneous perception of two images-
that of the object and that of the pencil. Various means have that of the object and that of the pencil. Various means have
been employed to arrive at this result. In that of Sömmering, it is a metallic mirror smaller than the pupil ; that of Amici is constructed on the principle of reflection on a plate with paral in a prism, of whick the edge, dividing the pupil in two parts, permits the object to be seen by the upper half. and simultaneously the pencil by the lower portion. In all these simultaneously the pencil by the lower portion. In all these
systems the fusion of the images is somewhat difficult to systems the fusion of the images is somewhat difficult to
seize, especially for certain points of the reflected image. Govi, Professor of Physics at the Royal University at Rome, proposes to cover with a thin layer of gold the reflecting
surface of a prism, and to apply upon this, with Canada bal. sam, a second prism with like angles. Although this layer of gold is sufficiently transparent to allow the luminous rays to pass, its power of reflection is considerable, a od it gives of superimposing, without fatigue to the eye, two different images-the one direct, and the other reflected. The principle is the application of that property of thin plates-metal lic or otherwise-to transmit simultaneouely direct ray and to reflect rays which arrive obliquely from another Dr.

Dr. Robertson, of Georgetown, Mass., thinks that the popular idea that hot or cold drinks are apt to crack the periment that it requires a chect. He has ascertained by exFah. to crack the enamel of an ordinary tooth. The teeth are never subjected to such a great change as this in the use of hot or cold liquids.

THE first passenger train making the complete circuit of St. Louis lately passed over the bridge and tbrough the tun-
nel. The regular locomotive being exchanged for one of the smoke consuming engines used by the tunnel company, the train passed as comfortably as though traveling in the open air.

The Saw Contest at Cincinnati.-In our account of the saw premium contest at the Cincinnati Exposition, the 16 good boards, $10 \times 20$, sawn in $t$ wo minutes and forty-four result than we reported.

THE Canadian way of measuring a tree is said to be as certain as it is grotesque. You walk from the tree, looking at it from time to time between your knees. When you are able to see the top of a tree in this way, your distance from the root of the tree equals its hight.

A LAwYeR's AdVICE To A PUPIL.-" When the facts are in your favor, but the law opposed to you, come out strong on the facts ; but when the law is in your favor, and the facts
opposed to you, come out strong on the law." "But," inquired he student, " when the law and the facts are both against me, wbat shall I do?" " Why, then," said the lawyer, " talk around them."

Leather PULP.-A process of pulping leather in engines, similar to those used for beating rags in a paper mill, is now in use in Massach usetts. By rolling it into eheets under con iderable pressure, a product of great tenacity, bomogeneity and closeness of texture is obtained, which is, moreover, per-
fectly waterproof. 